BMJ

Open

Gastroenterology

\title{
Hepatic macrophages in liver fibrosis: pathogenesis and potential therapeutic targets
}

\author{
Hai Li, ${ }^{1}$ Hong You, ${ }^{2}$ Xu Fan, ${ }^{3}$ Jidong Jia, ${ }^{2}$
}

To cite: Li H, You H, Fan X, et al. Hepatic macrophages in liver fibrosis: pathogenesis and potential therapeutic targets. BMJ Open Gastro 2016;3:e000079. doi:10.1136/bmjgast-2016000079

Received 10 January 2016 Revised 16 April 2016 Accepted 18 April 2016
${ }^{1}$ Department of

Hepatopancreatobiliary and Splenic Medicine, Affiliated Hospital, Logistics University of People's Armed Police Force, Tianjin, People's Republic of China

${ }^{2}$ Liver Research Center, Beijing Friendship Hospital, Capital Medial University, Beijing, People's Republic of China

${ }^{3}$ State Key Laboratory of Proteomics, Beijing Proteome Research Center, Beijing Institute of Radiation Medicine, Beijing, People's Republic of China

Correspondence to Dr Jidong Jia; jia_jd@ccmu.edu.cn

\section{ABSTRACT}

Hepatic macrophages account for the largest non-parenchymal cell population in the liver. Recent studies have found that hepatic macrophages have different functions in different stages of experimental liver fibrosis. Some studies found that there are different types of hepatic macrophages in the liver, although others have suggested that hepatic macrophages could switch to different phenotypes in different environments. Many studies demonstrated that while hepatic macrophages promoted fibrosis through the recruitment of proinflammatory immune cells, and the secretion of proinflammatory cytokines and chemokines in the early stages, these also promoted the resolution of hepatic fibrosis through the secretion of matrix metalloproteinases in the late stages. This article will review the current role played by hepatic macrophages in liver fibrosis and the potential therapeutic targets that modulate hepatic macrophages.

\section{INTRODUCTION}

Hepatic fibrosis is a dynamic process of repairing chronic liver injuries that may lead to cirrhosis and significant morbidity and mortality. ${ }^{1}$ Chronic necroinflammation activates hepatic stellate cells (HSCs) into myofibroblast-like cells, and the latter cells produce excessive extracellular matrix (ECM). Hepatic macrophages are a heterogeneous population of immune cells that perform diverse functions in homeostasis, and the progression and regression of chronic liver diseases. Recent studies with animal models of toxic or cholestatic liver fibrosis showed that hepatic macrophages can promote fibrogenesis via the initiation of fibrosis and sustain the phases of liver fibrosis, ${ }^{2}$ and can also promote fibrinolysis in the resolution phase. ${ }^{3}$

In this review, we will summarise the current understanding of the ambivalent roles played by macrophages in liver fibrosis, and will explore the potential targets of hepatic macrophages for treating liver fibrosis. ${ }^{4}$
The roles of hepatic macrophages in the pathogenesis of liver fibrosis

Hepatic macrophages play a central role in the pathogenesis of chronic liver injury, including inflammation and fibrosis. ${ }^{5}$ The phagocytic receptors in hepatic macrophages can be divided into membrane surface receptors and intracellular receptors. ${ }^{6}$ All of these receptors recognise and activate downstream molecules through different signalling pathways, thereby becoming involved in the processes of inflammation and fibrosis. ${ }^{7} 8$

Macrophages have different effects if their target cells are different. For example, phagocytosis of red blood cells causes iron deposition and induces oxidative stress reactions, which in turn promote inflammation and fibrosis; phagocytosis of collagen-producing cells and cell debris reduces inflammation and liver fibrosis. Furthermore, phagocytosis of apoptotic liver cells does not change the secretion of proinflammatory factors, although phagocytosis of necrotic liver cells causes the secretion of proinflammatory cytokines. ${ }^{9}$ This phenomenon may explain why macrophages do not promote fibrotic responses in normal conditions despite the fact that apoptosis of liver cells happens every day, ${ }^{10}{ }^{11}$ whereas hepatic macrophages produce inflammatory responses and liver fibrosis when hepatocyte necrosis occurs. ${ }^{12-17}$

A recent study showed that macrophage migration inhibitory factor (MIF) plays an important role in the early stages of liver fibrosis. ${ }^{6}{ }^{18}$ CCL4-induced liver fibrosis was more severe in MIF gene knockout mice than in wild-type mice. Some studies also found that sustained activation of hepatic nuclear factor $\kappa \mathrm{B}(\mathrm{NF} \kappa \mathrm{B})$ in macrophages led to liver inflammation and fibrosis, ${ }^{8} 19$ whereas killing hepatic macrophages significantly reduced NFKB activity and inflammation and fibrosis in the liver. ${ }^{7}$

Under the effects of tumour necrosis factor (TNF) and transforming growth factor 
$\beta 1$ (TGF- $\beta 1$ ), and C-C motif chemokine receptor 9 (CCR9) and C-C motif chemokine ligand 25 (CCL25), blood mononuclear cells accumulate in the liver and turn into classical macrophages (M1). ${ }^{20}{ }^{21}$ Some other molecules, such as CCL2 ${ }^{1522}$ and monocyte chemotactic protein 1 (MCP-1) are also involved in the chemotaxis of M1 proinflammatory macrophages, and thereby play an important role in the recruitment of $\mathrm{Ly}-6 \mathrm{C}+$ monocytes in liver fibrosis induced by CCL4. ${ }^{22}{ }^{23}$ Other studies also suggest that hepatic macrophage promoted liver fibrosis is mediated by CCL2, CCR8 and CCR9, and maintains NFKB activation in the early stage. ${ }^{2425}$

Many studies have suggested that hepatic macrophages have a two-way regulatory function ${ }^{2}$ in liver fibrosis; hepatic macrophages promote fibrosis through the recruitment of proinflammatory immune cells and the secretion of proinflammatory cytokines and chemokines in the early stages, whereas in the late stages, they promote the resolution of hepatic fibrosis through the secretion of matrix metalloproteinases (MMPs).

\section{The classification of hepatic macrophages in liver fibrosis}

Studies have suggested that macrophage activation may be classified into classic and alternative pathways-the M1 and M2 types of macrophages with helper T cell 1 (Th1) and helper T cell 2 (Th2) immune responses, respectively. ${ }^{26}{ }^{27}$ Both types of hepatic macrophages express the molecules CD68, CD163, and the monocytespecific molecule CD14; there is generally no expression or low expression of CD86 (dendritic cells) and CD3 ( $\mathrm{T}$ cells). ${ }^{26}$

M1 cells favour the Th1 response; secrete mainly TNF- $\alpha$, interleukin 1 (IL-1), IL-12, and reactive oxygen species (ROS) to remove bacteria; exert antiviral effects; and are also known as classical macrophages. ${ }^{28} \mathrm{M} 1$ cells are induced by interferon- $\gamma$ and IL-12, and these strongly express inducible nitric oxide syntheses (iNOS) and transglutaminase-2 (TGM-2) and weakly express arginase. ${ }^{29} \mathrm{M} 1$ cells also have phagocytic functions, promote inflammation and are involved in liver fibrogenesis.

M2 cells favour the Th2 response; secrete mainly the immunomodulatory cytokines TGF- $\beta 1$, IL-4, IL-13, and IL-10 to protect against parasite infections; and are also known as 'alternatively activated macrophages'. ${ }^{27}$ These are induced by IL- 4 and IL-13 or the hepatitis B virus. ${ }^{30}$ Rodent hepatic macrophages express chitinase-3-likeprotein 4 (YM-2) molecules, whereas human hepatic macrophages express CD206 and TGM-2 molecules. M2 cells secrete anti-inflammatory cytokines, including IL-10, to maintain the homeostasis of the intracellular environment and synthesise TGF- $\beta 1$ to maintain and promote the progression of liver fibrosis. ${ }^{30} 28$

There are at least two sources of hepatic macrophages: the liver itself (Kupffer cells) and circulating monocytes. Some studies found another group of macrophages different from these types of macrophages-the hepatic macrophages that may be derived from blood Ly-6Chigh mononuclear cells. ${ }^{23}$ Under the action of CX3CL1, these cells mature and turn into Ly-6C ${ }^{\text {low }}$ macrophages, ${ }^{31}$ which promote apoptosis of activated HSCs, and secrete MMP-12 and MMP-13 to promote ECM degradation. ${ }^{32}$ In clinical studies, patients with hepatitis or cirrhosis exhibited CD14 +CD16+ atypical macrophages in liver fibrosis tissue, and these cells may be derived from classical macrophages exhibiting CD14++CD16- in the microenvironment of the liver. ${ }^{27}$ This process appears similar to that of murine models, where Ly6Chigh mononuclear cells convert to Ly6C $^{\text {low }}$ hepatic macrophages in the liver. ${ }^{23}$

It is difficult to strictly separate the hepatic macrophages into these two subgroups because some of the cells express M1 and M2 molecules, suggesting that this classification is not fully applicable. Therefore, some scholars have suggested that hepatic macrophages may be functionally divided into defensive, restorative, and regulatory macrophages. ${ }^{27}$

Defensive macrophages, similar to M1 macrophages, are mainly activated by engulfing foreign pathogens; promote the production of inflammatory cytokines IL-1, IL-6 and IL-23; and promote T cell differentiation to Th17 cells, thus leading to inflammatory cell infiltration and causing apoptosis or necrosis. These cells may also cause some autoimmune diseases such as inflammatory bowel disease. ${ }^{33}$

Restorative macrophages induce IL-4 and CX3CL1. Tissue and cell injury, and natural killer (NK) cell activation can promote the differentiation of hepatic macrophages into this cell type. Restorative macrophages cannot effectively maintain their function by themselves because they do not sustainably secrete IL-4. Instead, these cells depend on the continuous secretion of IL-4 by eosinophils or antigen-specific $\mathrm{T}$ cells. Restorative hepatic macrophages are believed to be related to liver fibrosis regression. ${ }^{27} 34$

Regulatory macrophages are similar to M2 cells and are characterised by high expression of TGF- $\beta 1$ and IL-10, and can be activated by both phagocytosis and toll-like receptors (TLR). Although they express TGF- $\beta 1$, hepatic macrophages do not promote the progression of fibrosis because they also express IL-10, suggesting that the net effect of macrophages in liver fibrosis is governed by the overall levels of different cytokines.

However, it is not possible to fully distinguish various types of macrophages because one type of macrophage can be transformed into another type. Some hepatic macrophages secrete proinflammatory and antiinflammatory cytokines at the same time. Therefore, some scholars believe that macrophage subtypes do not exist, because cell types always change.

\section{Potential targets of hepatic macrophages to treat liver fibrosis}

Hepatic macrophages engage in close interactions with other non-parenchymal cells of the liver, especially HSCs. ${ }^{35}$ TGF- $\beta 1$ and platelet derived growth factor (PDGF) secreted by hepatic macrophages can activate HSCs to fibroblasts, and the latter can proliferate and 
secrete abundant collagens and other ECM, thereby causing liver fibrosis. ${ }^{37}$

As hepatic macrophages have such great variability and huge numbers (10-15\% of total liver cells), and also play important regulatory roles, these cells offer potential targets for treating liver fibrosis.

The first target involves preventing the infiltration of inflammatory mononuclear cells $(\mathrm{Ly}-6 \mathrm{C}+)$ through the inhibition of CCL2 (MCP-1) by RNA molecular technology, ${ }^{38}$ cleaning the intestinal tract with antibiotics to reduce the exposure of the liver to endotoxin, thereby reducing the infiltration of inflammatory cells. ${ }^{15}$ 38-40

The second target involves antagonising the inflammatory cytokines released from hepatic macrophages, such as IL-1 and TNF- $\alpha,{ }^{41}$ or promoting the apoptosis of activated HSCs, thereby attenuating hepatic fibrosis. ${ }^{42} 43$

The third target involves modulating the functional switch of hepatic macrophages via biological engineering of macrophages by nanoparticles ${ }^{44} 45$ or targeting drugs (dexamethasone vesicles) to control the functional transformation of hepatic macrophages. ${ }^{46}$

The fourth target involves promoting the functional restoration of macrophages by using CX3CL1 and IL-4 to accelerate the resolution of liver fibrosis. ${ }^{31}$ An ex vivo approach entails culturing peripheral blood monocytes in vitro under conditions favouring restorative hepatic macrophages $^{47}$ or other desired subtypes ${ }^{48}$ and then intravenously infusing the cells back into patients to alleviate liver fibrosis. ${ }^{49}$

Hepatic macrophages play a key role in the progression and regression of fibrosis, although there are still many unanswered questions that need further investigation. Finally, tailored yet standardised methods for the purification and identification of functionally heterogeneous hepatic macrophages are urgently needed to yield reproducible and communicable results that shed light on the pathogenesis of liver fibrosis and offer novel potential therapeutic targets for liver fibrosis. ${ }^{3} 30$

Contributors $\mathrm{HL}$ and $\mathrm{JJ}$ provided the ideas, and $\mathrm{HL}$ drafted the report. All the authors read and contributed to this manuscript's editing, agreed with the submission to BMJ Open Gastro, and agreed with the content and presentation of the manuscript.

Funding The Innovation Team Program (WHTD201310) is from the Logistics University of the Chinese People's Armed Police Forces; the National Natural Science Foundation of China, number 81173393; and the Natural Science Foundation of Tianjin City, grant number 12JCZDJC25500.

Competing interests None declared.

Provenance and peer review Commissioned; externally peer reviewed.

Data sharing statement No additional data are available.

Open Access This is an Open Access article distributed in accordance with the Creative Commons Attribution Non Commercial (CC BY-NC 4.0) license, which permits others to distribute, remix, adapt, build upon this work noncommercially, and license their derivative works on different terms, provided the original work is properly cited and the use is non-commercial. See: http:// creativecommons.org/licenses/by-nc/4.0/

\section{REFERENCES}

1. Lee YA, Wallace MC, Friedman SL. Pathobiology of liver fibrosis: a translational success story. Gut 2015;64:830-41.
2. Duffield JS, Forbes SJ, Constandinou CM, et al. Selective depletion of macrophages reveals distinct, opposing roles during liver injury and repair. J Clin Invest 2005;115:56-65.

3. Ramachandran P, Iredale JP, Fallowfield JA. Resolution of liver fibrosis: basic mechanisms and clinical relevance. Semin Liver Dis 2015;35:119-31.

4. Suk KT, Kim DJ. Staging of liver fibrosis or cirrhosis: the role of hepatic venous pressure gradient measurement. World $J$ Hepatol 2015;7:607-15.

5. Kazankov K, Barrera F, Moller HJ, et al. Soluble CD163, a macrophage activation marker, is independently associated with fibrosis in patients with chronic viral hepatitis B and C. Hepatology 2014;60:521-30.

6. Heinrichs D, Knauel M, Offermanns C, et al. Macrophage migration inhibitory factor (MIF) exerts antifibrotic effects in experimental liver fibrosis via CD74. Proc Natl Acad Sci USA 2011; 108:17444-9.

7. Shen $\mathrm{H}$, Sheng L, Chen Z, et al. Mouse hepatocyte overexpression of NF-kappaB-inducing kinase (NIK) triggers fatal macrophage-dependent liver injury and fibrosis. Hepatology 2014;60:2065-76.

8. Sunami Y, Leithauser F, Gul S, et al. Hepatic activation of IKK NFkappaB signaling induces liver fibrosis via macrophage-mediated chronic inflammation. Hepatology 2012;56:1117-28.

9. Dultz G, Gerber L, Farnik H, et al. Soluble CD163 is an indicator of liver inflammation and fibrosis in patients chronically infected with the hepatitis B virus. J Viral Hepat 2015;22:427-32.

10. Lodder J, Denaes T, Chobert MN, et al. Macrophage autophagy protects against liver fibrosis in mice. Autophagy 2015;11: 1280-92.

11. Olteanu S, Kandel-Kfir M, Shaish A, et al. Lack of interleukin-1alpha in Kupffer cells attenuates liver inflammation and expression of inflammatory cytokines in hypercholesterolaemic mice. Dig Liver Dis 2014;46:433-9.

12. Reiman RM, Thompson RW, Feng CG, et al. Interleukin-5 (IL-5) augments the progression of liver fibrosis by regulating IL-13 activity. Infect Immun 2006;74:1471-9.

13. Mathew J, Hines JE, Toole K, et al. Quantitative analysis of macrophages and perisinusoidal cells in primary biliary cirrhosis. Histopathology 1994;25:65-70.

14. Nakatsukasa $H$, Nagy $P$, Evarts RP, et al. Cellular distribution of transforming growth factor-beta 1 and procollagen types I, III, and IV transcripts in carbon tetrachloride-induced rat liver fibrosis. J Clin Invest 1990;85:1833-43.

15. Baeck $C$, Wei $X$, Bartneck $M$, et al. Pharmacological inhibition of the chemokine $\mathrm{C}-\mathrm{C}$ motif chemokine ligand 2 (monocyte chemoattractant protein 1) accelerates liver fibrosis regression by suppressing Ly-6C(+) macrophage infiltration in mice. Hepatology 2014;59:1060-72.

16. Van Rooyen DM, Larter CZ, Haigh WG, et al. Hepatic free cholesterol accumulates in obese, diabetic mice and causes nonalcoholic steatohepatitis. Gastroenterology 2011;141:1393-403, 1403.e1-5.

17. Suh YG, Kim JK, Byun JS, et al. CD11b(+) Gr1(+) bone marrow cells ameliorate liver fibrosis by producing interleukin-10 in mice. Hepatology 2012;56:1902-12.

18. Barnes MA, McMullen MR, Roychowdhury S, et al. Macrophage migration inhibitory factor is required for recruitment of scar-associated macrophages during liver fibrosis. J Leukoc Biol 2015;97:161-9.

19. Kitamura K, Nakamoto $\mathrm{Y}$, Akiyama M, et al. Pathogenic roles of tumor necrosis factor receptor p55-mediated signals in dimethylnitrosamine-induced murine liver fibrosis. Lab Invest 2002;82:571-83.

20. Chu PS, Nakamoto N, Ebinuma $\mathrm{H}$, et al. C-C motif chemokine receptor 9 positive macrophages activate hepatic stellate cells and promote liver fibrosis in mice. Hepatology 2013:58:337-50.

21. Sprenger $\mathrm{H}$, Kaufmann $\mathrm{A}$, Garn $\mathrm{H}$, et al. Induction of neutrophil-attracting chemokines in transforming rat hepatic stellate cells. Gastroenterology 1997;113:277-85.

22. Ehling J, Bartneck M, Wei X, et al. CCL2-dependent infiltrating macrophages promote angiogenesis in progressive liver fibrosis. Gut 2014;63:1960-71.

23. Ramachandran P, Pellicoro A, Vernon MA, et al. Differential Ly-6C expression identifies the recruited macrophage phenotype, which orchestrates the regression of murine liver fibrosis. Proc Natl Acad Sci USA 2012;109:E3186-95.

24. Yang L, Kwon J, Popov Y, et al. Vascular endothelial growth factor promotes fibrosis resolution and repair in mice. Gastroenterology 2014;146:1339-50.e1. 
25. Heymann F, Hammerich L, Storch D, et al. Hepatic macrophage migration and differentiation critical for liver fibrosis is mediated by the chemokine receptor $\mathrm{C}-\mathrm{C}$ motif chemokine receptor 8 in mice. Hepatology 2012;55:898-909.

26. Liaskou E, Zimmermann HW, Li KK, et al. Monocyte subsets in human liver disease show distinct phenotypic and functional characteristics. Hepatology 2013;57:385-98.

27. Tacke F, Zimmermann HW. Macrophage heterogeneity in liver injury and fibrosis. J Hepatol 2014;60:1090-6.

28. El HNM, Fahmy HM, Mohamed WA, et al. Relationship between vitamin D and IL-23, IL-17 and macrophage chemoattractant protein-1 as markers of fibrosis in hepatitis $\mathrm{C}$ virus Egyptians. World J Hepatol 2012;4:242-7.

29. Pesce JT, Ramalingam TR, Mentink-Kane MM, et al Arginase-1-expressing macrophages suppress Th2 cytokine-driven inflammation and fibrosis. PLoS Pathog 2009;5:e1000371.

30. $\mathrm{Li} \mathrm{H}$, Zheng HW, Chen $\mathrm{H}$, et al. Hepatitis $\mathrm{B}$ virus particles preferably induce Kupffer cells to produce TGF-beta1 over pro-inflammatory cytokines. Dig Liver Dis 2012;44:328-33.

31. Karlmark KR, Zimmermann HW, Roderburg $\mathrm{C}$, et al. The fractalkine receptor $C X(3) C R 1$ protects against liver fibrosis by controlling differentiation and survival of infiltrating hepatic monocytes. Hepatology 2010;52:1769-82.

32. Pellicoro A, Aucott RL, Ramachandran P, et al. Elastin accumulation is regulated at the level of degradation by macrophage metalloelastase (MMP-12) during experimental liver fibrosis. Hepatology 2012;55:1965-75.

33. Wijesundera KK, Izawa T, Tennakoon $\mathrm{AH}$, et al. M1- and M2-macrophage polarization in rat liver cirrhosis induced by thioacetamide (TAA), focusing on lba1 and galectin-3. Exp Mol Pathol 2014:96:382-92.

34. Pellicoro A, Ramachandran $P$, Iredale JP. Reversibility of liver fibrosis. Fibrogenesis Tissue Repair 2012;5(Suppl 1):S26.

35. Bility MT, Cheng L, Zhang Z, et al. Hepatitis B virus infection and immunopathogenesis in a humanized mouse model: induction of human-specific liver fibrosis and M2-like macrophages. PLoS Pathog 2014;10:e1004032.

36. Preisser L, Miot C, Le GH, et al. IL-34 and macrophage colony-stimulating factor are overexpressed in hepatitis $\mathrm{C}$ virus fibrosis and induce profibrotic macrophages that promote collagen synthesis by hepatic stellate cells. Hepatology 2014;60:1879-90.

37. Pradere JP, Kluwe J, De Minicis S, et al. Hepatic macrophages but not dendritic cells contribute to liver fibrosis by promoting the survival of activated hepatic stellate cells in mice. Hepatology 2013:58:1461-73.

38. Zhou X, Yang XF. Progress of targeting transforming growth factor-beta1 small interfering RNA in liver fibrosis. Chin Med Sci J 2014;29:231-5.

39. Patsenker E, Popov $Y$, Stickel F, et al. Pharmacological inhibition of integrin alphavbeta3 aggravates experimental liver fibrosis and suppresses hepatic angiogenesis. Hepatology 2009;50:1501-11.

40. Roderfeld M, Rath $\mathrm{T}$, Lammert $\mathrm{F}$, et al. Innovative immunohistochemistry identifies MMP-9 expressing macrophages at the invasive front of murine HCC. World $\mathrm{J}$ Hepatol 2010;2:175-9.

41. Choi HS, Kang JW, Lee SM. Melatonin attenuates carbon tetrachloride-induced liver fibrosis via inhibition of necroptosis. Transl Res 2015;166:292-303.

42. Jeong EJ, Kim NH, Heo JD, et al. Antifibrotic compounds from Liriodendron tulipifera attenuating HSC-T6 proliferation and TNF-alpha production in RAW264.7 cells. Biol Pharm Bull 2015;38:228-34.

43. Altrock E, Sens C, Wuerfel C, et al. Inhibition of fibronectin deposition improves experimental liver fibrosis. J Hepatol 2015;62:625-33.

44. Deng YR, Ma HD, Tsuneyama K, et al. STAT3-mediated attenuation of CCL4-induced mouse liver fibrosis by the protein kinase inhibitor sorafenib. J Autoimmun 2013;46:25-34.

45. Vollmar B, Siegmund S, Richter S, et al. Microvascular consequences of Kupffer cell modulation in rat liver fibrogenesis. J Pathol 1999;189:85-91.

46. Bartneck M, Scheyda KM, Warzecha KT, et al. Fluorescent cell-traceable dexamethasone-loaded liposomes for the treatment of inflammatory liver diseases. Biomaterials 2015;37:367-82.

47. Thomas JA, Pope C, Wojtacha D, et al. Macrophage therapy for murine liver fibrosis recruits host effector cells improving fibrosis, regeneration, and function. Hepatology 2011; 53:2003-15.

48. Toki $\mathrm{Y}$, Takenouchi $\mathrm{T}$, Harada $\mathrm{H}$, et al. Extracellular ATP induces $\mathrm{P} 2 \mathrm{X} 7$ receptor activation in mouse Kupffer cells, leading to release of IL-1beta, HMGB1, and PGE2, decreased MHC class I expression and necrotic cell death. Biochem Biophys Res Commun 2015;458:771-6.

49. Tanimoto $\mathrm{H}$, Terai $\mathrm{S}$, Taro $\mathrm{T}$, et al. Improvement of liver fibrosis by infusion of cultured cells derived from human bone marrow. Cell Tissue Res 2013;354:717-28. 